\title{
A Criatividade através da Expressão Musical: Uma Interface Gestual para Composição Musical Interativa
}

\author{
Ana Grasielle Dionísio Corrêa* \\ Roseli de Deus Lopes ${ }^{* *}$
}

Resumo. Este artigo apresenta uma Interface Gestual para Composição Musical que pode ser utilizado no apoio e complemento do ensino de música para iniciantes. A proposta apresentada utiliza movimentos do corpo para criação musical, afim de garantir ao aluno, uma boa educação rítmica, além de equilíbrio, prazer e alegria. O sistema é voltado ao desenvolvimento da criatividade no processo de criação musical, favorecendo para o surgimento de novas modalidades de ensino-aprendizagem relacionadas às formas de expressão corporal como meio de comunicação. Estes fatores propiciam na diversificação de Sistemas Interativos de Aprendizagem tornando-se uma importante justificativa em pesquisas na área de computação e música.

Palavras-chave: Educação Musical, Composição Musical, Sistemas Interativos de Aprendizagem, Interfaces Gestuais.

\begin{abstract}
This paper presents an Interactive System of Musical Composition that can be used as a support or a complement in the music education for beginners in the music learning. It's based on the idea that corporal movements possibilities used in the musical creation can guarantee a good rhythmic and musical education for the student, and also grant balance, pleasure and joy. The system is come back to the development of the creativity in the process of musical creation, favoring toward the sprouting of new related modalities of teach-learning to the forms of corporal expression as media. These factors propitiate diversification in the Interactive Learning Environment becoming an important justification in the computation and musical research areas.
\end{abstract}

Key words: Musical Education, Musical Composition, Interactive systems of Learning, Gesture Interfaces.

\footnotetext{
* Formada em Engenharia da Computação pela Universidade Católica Dom Bosco, Mestranda em Sistemas Eletrônicos pelo Laboratório de Sistemas Integráveis - Escola Politécnica - Universidade de São Paulo (USP), end: Av. Prof. Luciano Gualberto, travessa 3, n 380 - São Paulo (SP) Brasil, email: anagrasi@1si.usp.br, bolsista pela CAPES.

** Engenheira Eletricista, Mestre e Doutora pela Escola Politécnica da Universidade de São Paulo, Professora Assistente do Departamento de Engenharia de Sistemas Eletrônicos da EPUSP, end: Av. Prof. Luciano Gualberto, travessa 3, n 380 - São Paulo (SP) Brasil, email: roseli@ 1si.usp.br.
} 


\section{Introdução}

Estudos sobre gestos e movimentos corporais têm sido foco de pesquisas cada vez mais freqüientes no desenvolvimento de sistemas computacionais. Isto porque as inovações tecnológicas influenciam na exploração de diferentes recursos eletrônicos e computacionais para criação de interfaces gestuais (Machover, 2000). A evolução da Interface Homem-Computador favorece no desenvolvimento de sistemas de interpretação de imagens e sons, tornando tendência que o usuário interaja com o computador através de gestos ou comando de voz. Por meio destas inovações, buscamse novas modalidades de ensino-aprendizagem relacionadas às formas de expressão corporal como meio de comunicação e expressão, favorecendo na diversificação de Ambientes Interativos de Aprendizagem.

Estes avanços tecnológicos exigem uma transformação em todas as áreas do conhecimento. Na Educação, estas tecnologias influenciam ao surgimento de uma nova postura em relação ao processo de ensino-aprendizagem, possibilitando que os Meios Eletrônicos Interativos apresentem novos mecanismos que favorecem a esse processo (Ficheman, 2002). A finalidade é diversificar o desenvolvimento musical em sala de aula através de atividades musicais apoiadas por computadores e instrumentos eletrônicos.

Segundo (Zuffo, 2001), a definição de Meios Eletrônicos Interativos é o "acervo tecnológico orientado ao relacionamento sensitivo (audição, visão e tato) entre o usuário e uma infraestrutura computacional".

A música deve ser considerada como uma linguagem de expressão, colaborando no desenvolvimento de processos de aquisição de conhecimentos, sensibilidade, criatividade, sociabilidade e gosto artístico. Este momento criativo, onde o descobrir processos, pesquisar sons, combinar ritmos, melodias e harmonia, transforma-se em prazer e satisfação ao invés de regras de criação musical estipulado por alguns educadores.

Aliado a necessidade de exploração de recursos tecnológicos e ao incentivo da criatividade no processo de Educação Musical, o desenvolvimento de um Sistema Interativo de Expressão e Composição Musical tornou-se alvo deste trabalho.

\section{Educação Musical: Primeiros Passos}

\subsection{Conceitos Musicais}

A música é uma linguagem que organiza sons e silêncio no universo. Mas falar sobre os parâmetros do som não é falar sobre música. As características do som não podem ser interpretadas com sendo a própria música, mas a passagem do sonoro ao musical se dá pelo relacionamento entre os sons (e seus parâmetros) e o silêncio (Brito, 2003).

A música é composta por elementos, e estes são distintos entre: som, ritmo, melodia e harmonia. A seguir são apresentadas as caracterizações de cada um desses elementos (Lacerda, 2001):

- Som: representa tudo aquilo que impressiona o ouvido. É o resultado da vibração entre dois objetos ou dois corpos. Este por sua vez pode ser decomposto em vários elementos, sendo: altura, duração, intensidade e timbre. A seguir cada elemento é apresentado: 
1. Altura: refere-se aos sons médios, graves e agudos. São representados pelas notas musicais: dó, ré, mi, fá, sol, lá e si;

2. Duração: refere-se ao tempo de prolongamento do som. Pode ser curto ou longo e são representadas pelas figuras musicais;

3. Intensidade: refere-se ao volume do som;

4. Timbre: é a característica própria de cada som. É através do timbre que se sabe se uma música esta sendo executada, por exemplo, por um piano, violino, flauta, etc;

- Ritmo: movimento que ocorre em intervalos regulares. É conhecido também como cadência. O ritmo esta presente em todas as coisas, como por exemplo, na batida do coração, nos ponteiros do relógio, etc. O ritmo é independente da música, mas a música não dispensa o ritmo.

- Melodia: sucessão agradável de sons, formando o fraseado musical.

- Harmonia: combinação de sons simultâneos.

De acordo com (Brito, 2003), na música, a altura é o parâmetro relacionado à criação de linhas melódicas e harmonias. A duração conecta-se com a organização do ritmo. A intensidade encontra correspondente musical na expressão dinâmica e também no ritmo. O timbre personaliza, dá cor, caráter.

\subsection{O Processo de Criação Musical}

A criação musical ocorre por meio de dois eixos - a criação e a reprodução que garantem três possibilidades de ação: interpretação, improvisação e composição. A seguir são apresentadas cada uma destas possibilidades de ação (Brito, 2003):

- Interpretação: É a atividade ligada a imitação e reprodução de uma obra. Mas interpretar significa ir além da imitação por meio da ação expressiva do intérprete;

- Improvisação: Tratasse de criar instantaneamente, orientando-se por alguns critérios. Se para falar de improviso é preciso ter em mente o assunto, o domínio de um vocabulário, ainda que pequeno, assim como algum conhecimento de gramática, algo semelhante ocorre com a música. As idéias musicais vão e vem, transformando-se, recriando-se podendo ser trabalhadas e amadurecidas;

- Composição: É a criação musical caracterizada por sua condição de permanência, seja pelo registro na memória, seja pela gravação por meios mecânicos (fica cassete, CD), seja ainda, pela notação, isto é, pela escrita musical.

\section{Tecnologia e Música}

\subsection{O Computador como Ferramenta de Criação Musical}

A produção musical aliada à tecnologia vem favorecendo, ao longo dos anos, uma abrangência musical cada vez maior. Isto se deve à utilização de novos instrumentos e às novas formas de geração e produção de sons. Na atividade composicional, o computador apresenta-se como uma ferramenta que apóia o compositor na viabilização e explicitação de suas idéias. Através dos aplicativos computacionais o compositor tem acesso a sistemas de representação diversificados, 
que fornecem feedbacks sonoros e gráficos (partituras, desenhos e diagramas). O uso do computador na atividade musical apresenta possibilidades de criações, capturas e transformações de eventos sonoros (Ficheman, 2002).

Por este motivo, este trabalho fez uso desta tecnologia, aliada a exploração de pesquisas no desenvolvimento de interfaces gestuais, com a utilização de dispositivos eletrônicos capacitados a capturar ações gestuais e transmití-las ao computador para análise e parametrização sonora em tempo real.

\subsection{Sistemas Existentes}

Vários Centros e Institutos de Pesquisas desenvolvem projetos relacionados à integração multimídia entre usuários e máquinas no contexto da criação musical, dentre elas destacam-se o Media Lab do MIT (Massachussets Institute of Tecnology) e o NICS (Núcleo Interdisciplinar de Comunicação Sonora) da Unicamp. A seguir alguns trabalhos relacionados são apresentados.

\subsubsection{Media Lab}

O Media Lab é um Instituto de Pesquisa que prioriza o estudo, invenção e criação de novas tecnologias apoiadas pelo uso dos computadores e dispositivos eletrônicos no processo de produção musical. Técnicos do "Museum of the Future Media in Performance" criaram um sistema que sintetiza bem esta linha de pesquisa. Trata-se do DanceSpace. Um espaço interativo onde artistas possam gerar música e gráficos através de seus movimentos corporais. O dançarino se incorpora no espaço utilizando objetos que representam instrumentos musicais acoplados virtualmente a seu corpo. Cada objeto produz um som diferente, desta forma o dançarino tem a possibilidade de compor uma melodia como se estivesse fazendo mágica favorecendo ao processo de improvisação musical. Gráficos são gerados e projetados em uma tela dando forma a sua performance. No DanceSpace o artista não precisa utilizar nenhuma roupa especial. Seus movimentos são baseados excepcionalmente em processamento de imagens através de uma câmera direcionada em um espaço delimitado pelo sistema. Segundo (Sparatino et al, 1999), a principal motivação é o desenvolvimento de um sistema não-invasivo de captura de movimentos corporais que privilegia artistas com formas criativas de expressão corporal no processo de criação musical.

\subsubsection{NICS}

NICS significa Núcleo Interdisciplinar de Comunicação Sonora e vem atuando no desenvolvimento de projetos que visam o estabelecimento de relações entre computação e música. O Laboratório de Interfaces Gestuais (LIGA), por exemplo, estuda o desenvolvimento de instrumentos musicais eletrônicos e a criação de novas interfaces para vincular o som ao movimento e à dança. $\mathrm{O}$ resultado da pesquisa leva ao desenvolvimento de novas interfaces que utilizam a dinâmica do corpo no espaço para produzir eventos acústicos e visuais.

Um exemplo de sistema desenvolvido pelo LIGA é o Tapete Interativo. Tratase da criação de uma interface gestual, para interação com a música. É um tapete que possui a propriedade de localizar um ou mais corpos que estejam sobre sua superfície. De acordo com (Mialichi et al, 2002), o tapete em sua concepção, é composto por 256 peças no formato de triângulos eqüiláteros que, montados, podem assumir a forma de um tapete retangular ou qualquer outra forma que se queira produzir eventos acústicos e visuais. Sensores instalados nas peças reproduzem, com o auxílio do computador, 127 tipos de som. Ao tocar a superfície do tapete repetidamente com os pés, a pessoa gera uma sequiência sonora. A grande motivação para a implementação desse sistema 
segundo Mialichi (2000), é unir recursos de última geração com a expressão humana na produção musical.

\section{Sistema Interativo de Expressão e Composição Musical: um estudo de caso}

O Sistema Interativo de Expressão e Composição Musical é uma ferramenta para ser utilizada em aulas de música, como mais um instrumento de apoio às aulas de iniciação musical. Através dele, é possível utilizar os gestos do corpo como instrumento na produção de eventos sonoros. O sistema é voltado para crianças, jovens e adultos, inclusive pessoas portadoras de necessidades especiais. No caso de crianças, por exemplo, a partir dos três anos aproximadamente, os jogos com movimento representam possibilidade efetiva para o desenvolvimento motor e rítmico, sintonizados com a música, uma vez que o modo de expressão nessa fase integra o gesto, o som e o movimento (Brito, 2003).

Desta forma este sistema está sendo projetado para que o aluno desenvolva as seguintes capacidades:

- Ouvir, perceber e discriminar eventos sonoros diversos;

- Brincar com a música, imitar, inventar e reproduzir criações musicais;

- Identificar e explorar os elementos da música (timbre, intensidade, duração e altura) para se expressar, interagir com os outros e ampliar seu conhecimento musical;

- Criar, através do ritmo, uma corrente de comunicação rápida, regular e constante entre o cérebro e o corpo, percebendo e expressando sensações por meio de improvisações e transformando o sentido rítmico em uma experiência corporal física.

\subsection{Características do Sistema}

O objetivo do sistema é trabalhar com os elementos musicais: timbre, intensidade, duração e altura na criação musical.

O sistema identificará um espaço tridimensional, cujos eixos $\mathrm{X}, \mathrm{Y}$ e $\mathrm{Z}$, são associados a algum elemento musical. Desta forma, cada gesto representa a execução de um elemento musical reproduzido sobre uma determinada direção em seu respectivo eixo cartesiano. A duração é o próprio movimento, ou seja, enquanto prevalecer um determinado gesto no espaço, o som respectivo a ele se propagará permanentemente. Os elementos intensidade e altura, por exemplo, podem estar associados a alguma parte do corpo cuja finalidade é alterar um ritmo estabelecido pelo usuário no acompanhamento da performance.

O professor determinará o arranjo entre as partes do corpo, os elementos musicais e os eixos. Após as configurações, o aluno poderá executar movimentos do corpo para criação musical. Os sons produzidos serão transformados em gráficos projetados em uma tela situado à frente do usuário. A Figura 4.1.1 ilustra o cenário do sistema. 


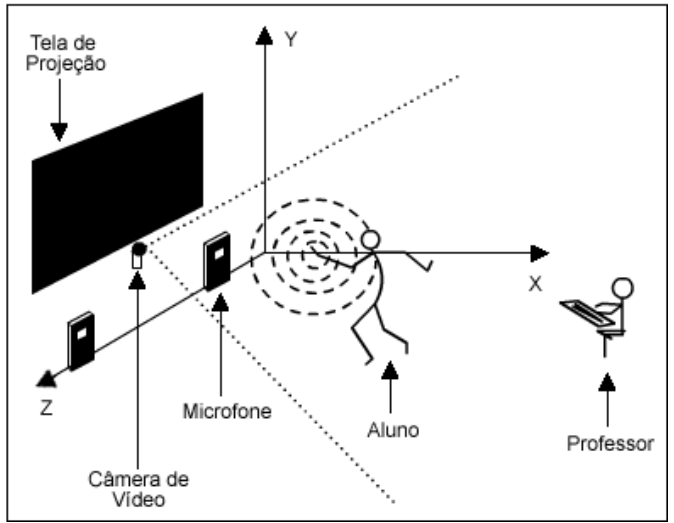

Figura 4.1.1 - Ambiente do sistema de composição musical gestual.

No exemplo da Figura 4.1.2, por exemplo, somente a mão esquerda na direção vertical está relacionada ao timbre, desta forma, a mão direita ou um dos joelhos, podem ser associados para que alterem o ritmo escolhido nesta performance. Através do elemento musical altura, por exemplo, movimentos da mão direita na vertical para cima tornam o ritmo mais agudo e para baixo, mais grave. Desta forma, enquanto uma mão trabalha com o ritmo da performance, a outra produz um timbre. O objetivo é batucar em uma melodia pré-estabelecida (o ritmo). O ideal é associar partes do corpo a vários timbres em várias direções, enriquecendo a performance musical. Neste momento o corpo se transforma em instrumento na produção sonora. O sistema dispõe de configurações onde se pode determinar as partes do corpo que se quer trabalhar (mãos e joelhos), a quantidade de gestos sobre um eixo e quais elementos musicais estará relacionado a uma determinada performance.

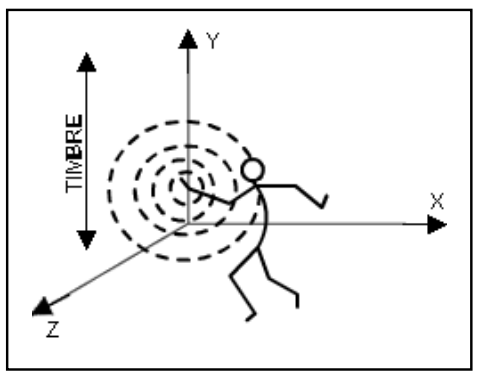

Figura 4.1.2 - Exemplo de performance, cuja mão esquerda está relacionada ao elemento musical timbre no eixo Y.

As características principais do sistema são:

- Possibilidade de escolher e configurar os dispositivos de entrada do sistema. Além dos dispositivos de captura de movimento como sensores e câmeras, o sistema dispõe de dispositivos como joystick, mouse e teclado para realizar simulações;

- Disponibilidade de uma biblioteca com vários estilos de músicas eletrônicas para acompanhamento da performance;

- Possibilidade de importação e alteração das músicas eletrônicas disponíveis na biblioteca de ritmos. Permite o ajuste da freqüência do ritmo, ou seja, pode-se diminuir ou acelerar as batidas de uma música eletrônica escolhida para execução da performance tornando-a mais lenta ou mais rápida;

- Possibilidade de escolher a animação para execução da performance; 
Os elementos da interface que compõe o sistema são: Configurar Entrada, Gerenciar Ritmos e Executar. Nas próximas subseções cada um destes elementos é apresentado.

\subsection{Configurar Entrada}

A interface principal do Sistema Interativo de Expressão e Composição Musical, ilustrada na Figura 4.2.1, é composta por três guias. A primeira guia "configurar entrada" possui as opções de configurações dos elementos de entrada do sistema e uma janela onde contém um personagem tridimensional.

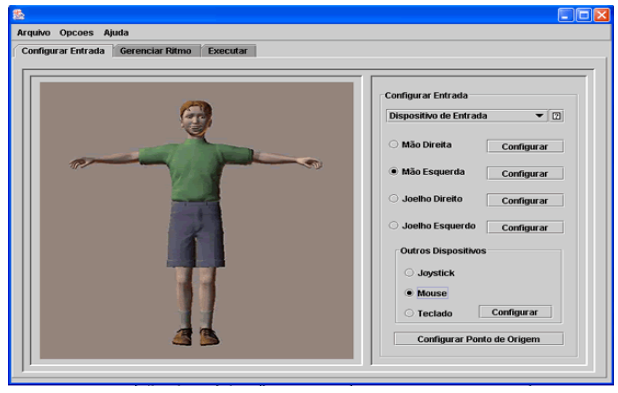

Figura 4.2.1 - Configurar entrada.

A Figura 4.2.2 ilustra as funcionalidades da guia "configurar entrada". A seguir cada uma delas é apresentada.

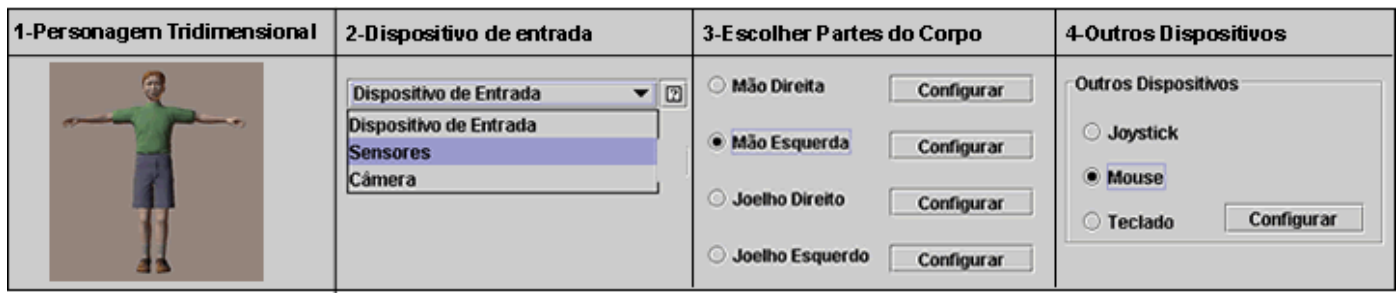

Figura 4.2.2 - Funcionalidades da guia "configurar entrada".

1. Personagem Tridimensional: A janela tridimensional possui um personagem cujas mãos e joelhos estão destacados indicando que somente estas partes do corpo podem ser configuradas para criação da performance musical. O usuário deve escolher as partes de seu corpo como instrumento em sua composição. Ao clicar em uma das partes do corpo do personagem, ou selecionando-as a partir das opções expostas na caixa de ferramentas "escolher partes do corpo", o usuário terá a opção de configurá-la como mostrado no item três a seguir.

2. Dispositivos de Entrada: Os dispositivos de captura dos movimentos são sensores e câmeras. No caso dos sensores, por ser um sistema invasivo, o usuário deverá estar conectado a dispositivos eletrônicos em seu corpo cujos movimentos serão capturados, processados, parametrizados e transformados em sons. No caso das câmeras, o usuário deverá utilizar marcadores posicionados em seu corpo para o processamento das imagens. A vantagem de se utilizar câmeras é que o sistema não é invasivo.

3. Escolher Partes do Corpo: Através desta caixa de ferramentas, o usuário também poderá selecionar a parte do corpo ao qual irá produzir sons. A partir disso terá de configurar esta entrada para trabalhar com os elementos musicais: 
timbre, intensidade e altura como ilustra a Figura 4.2.3.. A seguir cada uma das configurações é apresentada.

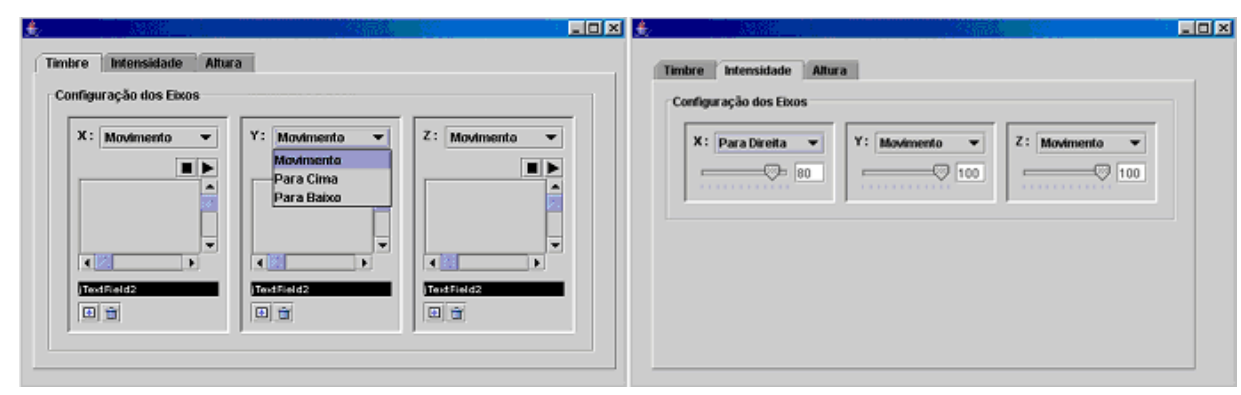

Figura 4.2.3 - Configurar os eixos e seus Elementos Musicais.

- Configurar Timbre: Esta janela contém alguns arquivos no formato wav (Waveform Audio) que representam os sons que cada membro do corpo irá executar. $\mathrm{O}$ arquivo wav é um tipo de formato onde o som é armazenado através de seqüências numéricas. Este formato é o mais utilizado na digitalização de sons, pois pode ser facilmente editado e possui uma alta qualidade em relação a outros formatos. Além dos sons já existentes, o sistema possibilita ao usuário adicionar e remover sons da biblioteca de sons. Se o usuário decidir trabalhar com o timbre na mão direita, por exemplo, então deverá selecionar o(s) eixo(s) e seus respectivos movimentos. No eixo $\mathrm{X}$, os movimentos deverão ter sentido horizontal direito e esquerdo. $\mathrm{O}$ eixo $\mathrm{Y}$ deverá ter movimentos verticais para cima e para baixo, e o eixo $\mathrm{Z}$ deverá ter movimentos para frente e para trás.

- Configurar Intensidade: Esta janela contém a opção de configuração da intensidade do som. Os eixos continuam com as mesmas opções de direção. A Figura 4.2.3 ilustra um exemplo de configuração da mão direita no eixo $\mathrm{X}$, no sentido horizontal para direita com a intensidade do som de $80 \mathrm{db}$, ou seja, movimentos na direção horizontal alcançarão volume do som de $80 \mathrm{db}$.

- Configurar Altura: A configuração da altura do som é idêntica a opção "configurar intensidade" apresentado anteriormente, porém, o objetivo é alcançar um som mais grave ou mais agudo.

Obs: Cada parte do corpo pode ser configurada para trabalhar em apenas um eixo ou em todos os eixos (X, Y e Z). Cada eixo com um tipo de elemento musical, ou pode-se repetir um mesmo elemento musical em todos os eixos, como o timbre, por exemplo. Cada movimento, em uma determinada direção, produz um som diferente. Cabe ao professor, identificar em cada caso, o elemento a ser utilizado na criação musical. Caso se deseje somente trabalhar com altura e intensidade, deve-se então escolher um acompanhamento na biblioteca de ritmos para que os gestos correspondentes a estes alterem a música eletrônica em termos de altura e intensidade. O funcionamento desta biblioteca de ritmos está descrito na próxima sessão.

4. Outros Dispositivos: Esta opção permite ao usuário realizar uma simulação da performance musical. A desvantagem é que dispositivos como o mouse, por exemplo, possui somente dois eixos, $\mathrm{X}$ e $\mathrm{Y}$, não possui profundidade, ou seja, o eixo Z. Estes detalhes devem ser levados em consideração na hora das configurações. Existe um botão "configurar" onde, dependendo do dispositivo escolhido, abrirá uma nova janela contendo as opções de configurações de cada dispositivo. No caso do teclado, existe a possibilidade de associar cada movimento e seus elementos musicais a uma tecla do teclado. O mouse também 
contém informações de como associar os eixos $\mathrm{X}$ e $\mathrm{Y}$ a movimentos do corpo e seus elementos musicais. O mesmo para o Joystick.

\subsection{Gerenciar Ritmo}

A interface da guia "gerenciar ritmo", dispõe de uma biblioteca de músicas eletrônicas no formato wav. O sistema possibilita ao usuário adicionar e remover arquivos wav da biblioteca de ritmos. O usuário poderá modificar o ritmo de acordo com a quantidade de batidas por minuto, ou seja, pode torná-la mais lenta ou mais rápida de acordo com a performance desejada. Obtendo o ritmo desejado, o próximo passo é salva-lo e adicioná-lo na biblioteca de ritmos. No momento da execução, este ritmo permanecerá em um loop até a finalização da performance.

\subsection{Executar}

A interface da guia "executar", possui uma janela de animação interativa onde o usuário, ao executar uma performance, poderá gerar cores musicais através de seus movimentos corporais. As cores do som levam à sinestesia, ou seja, é uma mensagem que possui cor e textura. Através da vibração de um timbre, pode-se perceber a música como sendo áspera, macia, calma, branca, azul, multicolor, etc.

Após realizar todas as configurações anteriores, o usuário poderá criar músicas através de seus movimentos corporais, observando as cores de cada som produzido por seus gestos. A performance poderá ser salva como arquivo wav. Após o término da execução, o aluno poderá visualizar sua composição audiovisual. Existem vários tipos de animações, possibilitando que o usuário possa executar os mesmos gestos com animações em formas diferentes.

\section{Resultados Preliminares}

Embora o Sistema Interativo de Expressão e Composição Musical não esteja totalmente em funcionamento, foram realizados testes com dispositivos como mouse e teclado. As entradas foram configuradas para trabalhar com os elementos musicais nos eixos X e Y. Os testes estão sendo feitos a partir de simulações de gestos onde futuramente poderão ser captados por dispositivos eletrônicos. Estudos e testes sobre sensores e processamento de imagens estão sendo realizados para a conclusão da etapa de captura de movimentos para produção sonora.

Dentre os sensores pesquisados, destacam-se:

- Espaciais: infravermelho, ultra-som e LDR;

- Campo Magnético: sensores de efeito Hall;

- Vibrações: interruptores de mercúrio e microfones.

Os sensores de efeito Hall são dispositivos semicondutores que exibem uma diferença de potencial em função de um campo magnético aplicado. Os ultra-sons podem ser utilizados para medir distâncias entre um emissor e um receptor de frequiências acima do limiar da audição. Os infravermelhos são sensores de posição que trabalham com frequiências abaixo do limiar de visibilidade humana. O sensor LDR (Light Device Resistor), tem sua resistência modificada em função da luminosidade captada (Mialichi et all, 2002).

Por meio de Processamento Digital de Imagens, a técnica de captura de movimentos também está em desenvolvimento. Basicamente constitui em um processo de amostragem, onde a posição e a orientação de marcadores posicionados no corpo do 
usuário, ao entrarem em movimento, são captados por uma câmera de vídeo, enviados a um computador para posteriormente ser digitalizada, parametrizada e inserida em um sistema de composição musical interativa.

\section{Considerações Finais}

Apresentou-se neste trabalho o desenvolvimento de uma interface interativa de criação musical e seu aproveitamento como apoio ou recurso pedagógico em aulas de iniciação musical. $O$ sistema oferece a possibilidade de construção de um acompanhamento rítmico (alteração de uma música eletrônica) disponível na biblioteca de ritmos, onde o usuário poderá compor sobre ela através de movimentos corporais.

Para trabalhos futuros, é pretendida uma adaptação para que o sistema seja capaz de ler uma entrada em forma de partitura musical, auxiliando alunos iniciantes em aulas de percepção musical na reprodução de batidas rítmicas durante um ditado rítmico. As batidas rítmicas deverão ser executadas por movimentos corporais.

\section{Referências Bibliográficas}

Brito, T. A. Música na Educação Infantil. São Paulo: Peirópolis, 2ª edição - 2003.

Ficheman, I. K. Aprendizagem Colaborativa a Distância Apoiada por meios Eletrônicos Interativos - um estudo de caso em educação musical, no Estado de São Paulo. São Paulo: Poli/USP, 2002. Dissertação de mestrado.

Lacerda, O. Teoria Elementar da Música. São Paulo: Ricordi, 12a edição - 1996.

Machover, T. Musical Sound Information - Musical Gesture and Embedding Synthesis. Cambridge, MA. Related Research at the MIT Media Lab - Massachusetts Institute of Tecnology, 2000.

Mialichi, J. R. e Manzolli, J. Estudo e Desenvolvimento de Interface Gestual para

Composição Interativa. No Estado de São Paulo. Campinas: NICS - Unicamp, 2002. Projeto de Iniciação Científica .

Sparacino, F.; Davenport, G. and Pentland A. Augmented Performance in Dance and Theater. Arizona State University. International Dance and Technology 99 (IDAT99), 1999.

Zuffo, M. K. A Convergência da Realidade Virtual e Internet Avançada em Novos

Paradigmas de TV Digital Interativa, 91p, no Estado de São Paulo. São Paulo: Poli/USP, 2001. Tese de Livre Docência.

Weinberg, G. Playpens, Fireflies and Squeezables: New Musical Instruments for Bridging the Thoughtful and the Joyful. Music Journal, MIT Media Lab Laboratory Massachusetts Institute of Tecnology , 2002. 